\title{
Is conversation partner training effective in assisting individuals with a traumatic brain injury to display improved communication outcomes
}

\section{Gilly-Elle Wiltshire}

CONROD

Griffith University

\section{Carolyn Ehrlich}

CONROD

Griffith University

\begin{abstract}
Background: People who experience Traumatic Brain Injury (TBI) often exhibit a range of communication difficulties following their injury. Conversation is a vital component of communication that can have wide-ranging effects on social and vocational roles. Conversation ability is often negatively affected by a brain injury. It has been suggested that training the conversation partners of people with TBI can be effective in improving communication outcomes, therefore, positively affecting quality of life. This is the first systematic review investigating the efficacy and effectiveness of conversation partner training with this population.

Method: After appropriate search terms were chosen, Medline, Psychinfo, CINAHL and Speechbite databases were searched to find appropriate articles for inclusion in the review. Papers underwent a three step screening process (title, abstract and full text) to be included in the study. Data were extracted and summarised.

Results: Although only four studies were included in the final review, all showed
\end{abstract}


positive effects of training in relation to a range of conversation partners for people with $\mathrm{TBI}$, including family, carers and shop assistants. Training programs varied in method and outcome measures, but all provided support for the inclusion of communication partner training in TBI rehabilitation.

Conclusion: Conversation partner training can be an effective intervention for people with TBI. More studies with larger sample sizes would add strength to conclusions and provide more informed basis for clinical practice. Recommendations for future research and practice are provided.

Keywords: Traumatic brain injury, conversation partner training, rehabilitation, measurement tool

\section{Introduction}

Traumatic brain injury (TBI) affects ten million people worldwide (Hyder, Wunderlich, Puvanachandra, Gururaj, \& Kobsingye, 2007) and, in Australia, 2,500 new injuries occur annually (Togher, 2014). Although TBI can occur through various incidents, the most common cause is motor vehicle accidents (Australian Intitute of Health and Welfare $[\mathrm{AlHW}], 2007)$. The majority of these injuries occur when young people are embarking upon career and relationship development (i.e., between 18-25 years of age; Tate, McDonald, \& Lulham, 1998). TBI commonly results in difficulties with cognition, speech, mental health and intellectual functioning (AlHW, 2007); which are significant life changing complications. In addition to these individual challenges, wider negative influences are created by the huge financial burden on governments worldwide (Yasuda, Wehman, Targett, Cifu, \& West, 2001). In Australia, the estimated economic costs of TBI are $\$ 8.6$ billion per year (Access Economics, 2009), primarily due to lost productivity, as people with a TBI face challenges in returning to work or require considerable time off for rehabilitation (Cifu, Cohen, Lew, Jaffee, \& Sigford, 2010).

Difficulties with communication following TBI occur for up to 70 percent of individuals with TBI. These cognitive-speech disorders can have severe adverse effects on the maintenance of employment and friendships (Togher, 2014). In a 2007 survey, 39 percent of people with TBI aged under 65 exhibited a sensory/speech disability (AIHW, 2007). Communication is vital to the expression of our identity and 
daily conversation is an important aspect of this process. Armstrong and Mortensen (2006) highlighted the centrality of conversation to social competence. Conversational ability has been found to be severely impaired in people following a TBI (Leblanc et al., 2014). Conversational difficulties that may be exhibited by someone with a TBI include difficulties with pragmatic language (Douglas, Bracy, \& Snow, 2007), organization of thoughts (Coelho, Grelad, Corso, Gamble, \& Fenn, 2005), content management (Moran, Nippold, \& Gillon, 2006) and word finding (Jurado, Mataro, Verger, Bartumeaus, \& Junque 2000). People with TBI experience embarrassment, shame, distress and fear regarding their impaired ability to communicate (Durham, 2014), which is likely to inhibit their natural inclusion in social contexts.

Improving conversation ability is likely to have important ramifications for people with TBI, particularly in relation to successful return to work. A recent review undertaken by van Velzen, van Bennekom, Edelaar, Sluiter, and Frings-Dresen (2009) found that only 40 percent of people with TBI were able to return to work within two years of their injury. Those who are able to work are often advised to accept a different role to their pre-injury position, usually with reduced responsibility. Inability to perform as they did before their injury and a reliance on government funds can be distressing, so it is important to facilitate opportunities and skills that enable people to resume their professional responsibilities and desired career despite their injury.

Social relationships make an important contribution to quality of life and loss of social relationships was the most devastating long-term impact of TBI (Dahlberg et al., 2007). Shorland and Douglas (2010) found that the social relationships of people with a TBI could be enhanced by simple improvements in conversational abilities. Hoofien, Gilboa, Valik, and Donovick (2001) surveyed people with TBI and found that 31 percent reported having no friends. There was also a high divorce rate within this sample. These statistics indicate the potential importance of improving conversation skills to sustain social relationships and increase social networks in order to improve quality of life and improve mental health outcomes (Chan, Parmenter, \& Stancliffe, 2009).

Following discharge from hospital, family members of people with TBI are given little support and many believe that they require additional information and training. Carers are likely to feel overwhelmed and uncertain how best to help their 
loved one, which is significant given that 97 percent of people with TBI under the age of 65 live with their families (AlHW, 2007). Not surprisingly, depression and anxiety are present in almost one quarter of caregivers of people with TBI (Kreutzer, Stejskal, Ketchum, Marwitz, Taylor, \& Menzel, 2009).

Granlund, Bjorck-Adesson, Wilder and Ylven (2008) recognized the importance of building stronger relationships between professionals, family members and people with TBI. Given that Kendall and Terry (2009) discovered a strong link between long-term emotional well-being and family support, involving families in rehabilitation programs may be fundamental to improved outcomes. However, family relationships can be strained following any significant trauma, but assistance should be offered to the family so they can provide appropriate support (Hepburn, Tornatore, Center, \& Ostwald, 2001). Training family members to become meaningful conversation partners may be an appropriate way to increase family involvement in rehabilitation.

Training of conversation partners began in the 1990s and is now a wellestablished intervention strategy in the area of aphasia rehabilitation following stroke, where it has been shown to have good outcomes (Simmons-Mackie, Raymer, Armstrong, Holland, \& Cherney, 2010; Wilkinson, Bryan, Lock, \& Sage, 2010). To date, this evidence has not been well translated to the TBI field. Wallace and Bradshaw (2011) summarized the ways in which a conversation partner can help improve communication outcomes for people with $\mathrm{TBI}$; including reducing the number of questions, patience, and using an age appropriate style. Environmental modifications are also important, including finding a quiet place for conversations, reducing the number of people involved and removing distractions.

Research into the effectiveness of conversation partner training in the TBI population is in its infancy. Initial evidence has indicated that it could be beneficial (Togher, McDonald, Code \& Grant, 2004; Welch-West et al., 2007; Ylvisaker, 2006). An important aspect of conversation partner training programs is the type of conversation partner. For instance, a case study published by Vy Tu, Togher and Power (2011) found important differences in the nature of information exchange and style of communication between a 19 year-old man with TBI and his mother or a paid caregiver. Familiarity could, therefore, be an important aspect of a successful conversational partnership with familiar conversation partners being more accurate in their assessment of conversation ability and greater awareness of difficulties. 
However, conversation partners do not necessarily have to be familiar to be effective, as Behn, Togher, Power, and Heard (2012) discovered when investigating the role of paid caregivers in facilitating the communication skills of people with TBI. The implications of these studies include the need to carefully choose conversation partners for each individual and the importance of raising awareness of difficulties that might be encountered.

Although conversation partner training has been recommended by international experts in TBI speech pathology (Togher, 2014), to date, there has been no systematic review to determine whether or not conversation partner training is effective for people with TBI. This review explores the limited evidence base for training the conversation partners of individuals with TBI.

\section{Method}

\section{Search Strategy}

Four databases (Medline, CINAHL, Psycinfo and Speechbite) were searched using a total of 14 terms related to conversation partner training in TBI namely: (brain injury OR head injury OR TBI OR ABI OR head trauma OR brain trauma) AND (speech loss OR nonverbal OR communication impairment OR communication disorder OR non communicative OR complex communication need) AND (communication partner OR conversation partner). Following the initial searches, a total of 23 articles were identified for inclusion in the review (Figure 1). Three duplicates were removed and 20 abstracts were reviewed for relevance. Articles were included for full text analysis if the studies met the following criteria: (1) participants were 18 years of age and over and were identified as having a TBI, (2) the intervention focused on training conversation partners, (3) written in English, (4) the full text article was available, and (5) published in the last decade since 2004. Although 20 studies were identified as being potentially relevant to this review (Figure 1), 16 were excluded on the following basis: three papers included participants under 18 years of age, 12 studies focused on conversation partners, but did not include an intervention, and one study could not be located despite attempts to contact the author.

Figure 1. Flow diagram showing process of study selection.

Records identified through database searching $(n=23)$ 


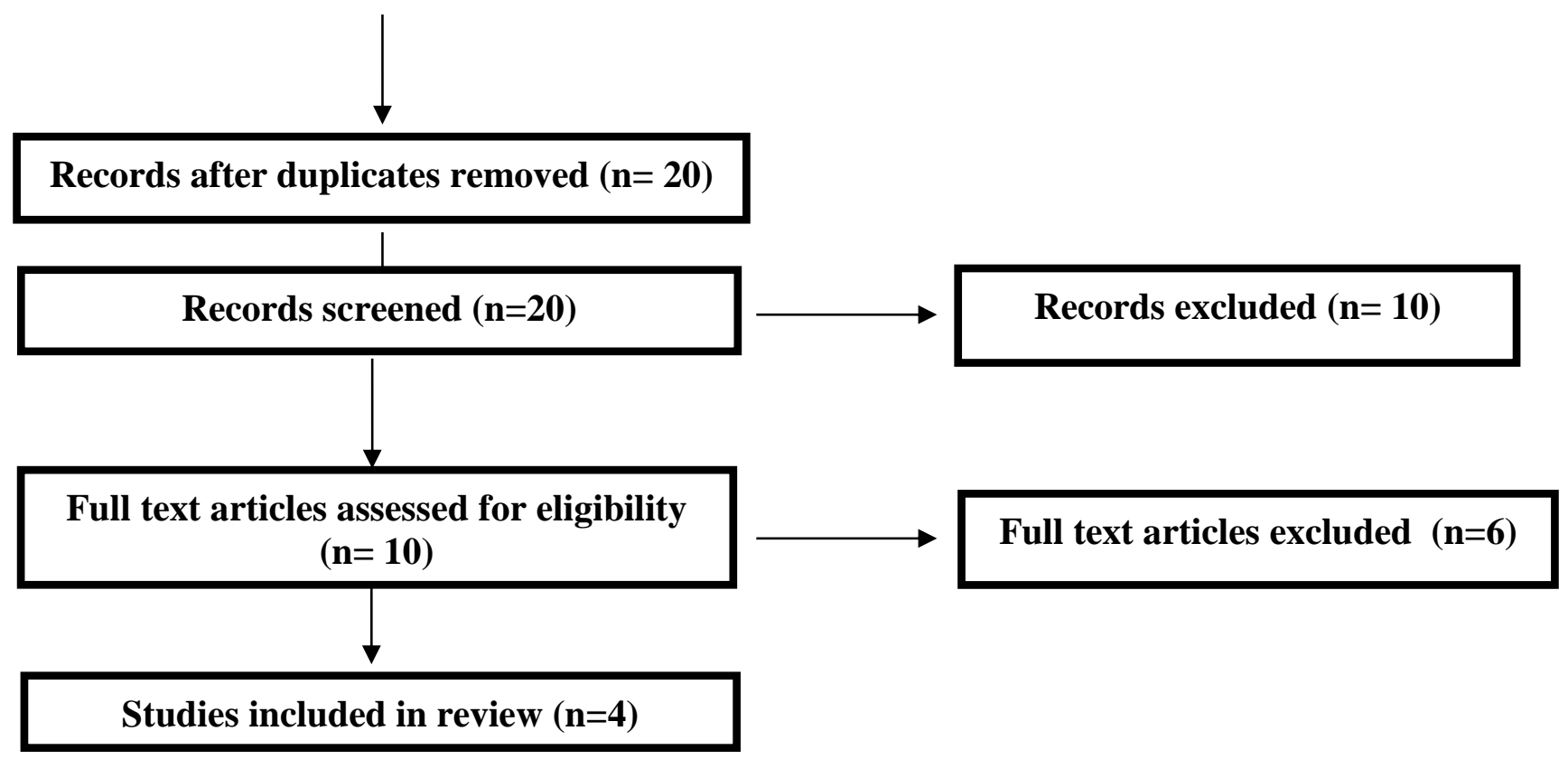

The following data was extracted from all articles included for final review: publication details (i.e. authors, publication date and place of publication), sample size, participant characteristics (i.e., type of injury, severity, sex, age, time since injury), intervention method, outcome measures, and results. Details of the studies are included in Table 1.

Table 1

Analysis of studies relevant to conversation partner training for TBI.

\begin{tabular}{|c|c|c|c|c|}
\hline Study & Population & Intervention & Comparison & Outcomes \\
\hline $\begin{array}{l}\text { Togher et al., } \\
\text { (2012); Australia }\end{array}$ & $\begin{array}{l}\text { Qualitative study of } \\
\text { participants from } \\
\text { previous study. } 13 \\
\text { assigned to joint } \\
\text { group and } 14 \text { to } \\
\text { solo group. }\end{array}$ & $\begin{array}{l}\text { Interviews with each } \\
\text { group conducted to } \\
\text { discuss training } \\
\text { provided in Togher et } \\
\text { al (2013) study. }\end{array}$ & $n / a$ & $\begin{array}{l}\text { Conversation partner } \\
\text { important factor in } \\
\text { sustaining positive } \\
\text { communication styles } \\
\text { post training for two } \\
\text { important reasons: } \\
\text { (1) assisted with } \\
\text { increasing intensity of } \\
\text { practice between } \\
\text { sessions, and (2) } \\
\text { their intact executive } \\
\text { functioning assisted } \\
\text { with gradual } \\
\text { incorporation of } \\
\text { learned strategies } \\
\text { over time. Also, } \\
\text { training programs that } \\
\text { combined both group } \\
\text { and individual } \\
\text { sessions were } \\
\text { believed to be } \\
\text { advantageous to } \\
\text { achieving change. }\end{array}$ \\
\hline
\end{tabular}




\begin{tabular}{|c|c|c|c|c|}
\hline $\begin{array}{l}\text { Togher et al. } \\
\text { (2013); Australia }\end{array}$ & $\begin{array}{l}44 \text { TBI participants } \\
\text { from Sydney, } \\
\text { Australia }\end{array}$ & $\begin{array}{l}\text { Non-randomised } \\
\text { control trial. } 3 \text { groups } \\
\text { - people with TBI } \\
\text { and conversation } \\
\text { partner dyads, } \\
\text { people with TBI only } \\
\text { and a control group } \\
\text { comprising people } \\
\text { with TBI and } \\
\text { conversation partner } \\
\text { dyads. Weekly } \\
\text { conversation skills } \\
\text { training offered to } \\
\text { joint and solo groups. }\end{array}$ & $\begin{array}{l}\text { Control group } \\
\text { received no skills } \\
\text { training }\end{array}$ & $\begin{array}{l}\text { Dyad intervention } \\
\text { group was not only } \\
\text { significantly more } \\
\text { effective than training } \\
\text { people with } \mathrm{TBI} \text { in } \\
\text { communication skills } \\
\text { alone, but the people } \\
\text { with TBI without } \\
\text { conversation partners } \\
\text { did not show any real } \\
\text { benefit from the } \\
\text { training over time. }\end{array}$ \\
\hline $\begin{array}{l}\text { Sim, Power \& } \\
\text { Togher (2013); } \\
\text { Australia }\end{array}$ & $\begin{array}{l}29 \text { participants from } \\
\text { Sydney, Australia. } \\
14 \text { in joint group and } \\
15 \text { in control group }\end{array}$ & $\begin{array}{l}\text { Non-randomised } \\
\text { control trial. Weekly } \\
\text { social communication } \\
\text { training offered to } \\
\text { people with TBI and } \\
\text { a conversation } \\
\text { partner dyad. Social } \\
\text { communication } \\
\text { training comprised } 2 \\
1 / 2 \text { hours group } \\
\text { training and } 1 \text { hour } \\
\text { individual training } \\
\text { each week for } 10 \\
\text { weeks. Control group } \\
\text { received intervention } \\
\text { after completion of } \\
\text { study. }\end{array}$ & $\begin{array}{l}\text { Control group } \\
\text { received no skills } \\
\text { training }\end{array}$ & $\begin{array}{l}\text { Positive outcomes in } \\
\text { communication styles } \\
\text { were shown in the } \\
\text { intervention group. } \\
\text { Conversation } \\
\text { partners showed } \\
\text { improved } \\
\text { collaborative and } \\
\text { elaborative } \\
\text { communication } \\
\text { strategies and were } \\
\text { better able to scaffold } \\
\text { conversations and } \\
\text { encourage } \\
\text { contribution from } \\
\text { person with TBI. }\end{array}$ \\
\hline $\begin{array}{l}\text { Goldblum \& } \\
\text { Alant (2009); } \\
\text { South Africa }\end{array}$ & $\begin{array}{l}70 \text { supermarket } \\
\text { staff from national } \\
\text { chain }\end{array}$ & $\begin{array}{l}\text { Randomised control } \\
\text { trial. Experimental } \\
\text { group received } 4 \\
\text { hours of video } \\
\text { training on being a } \\
\text { more effective } \\
\text { conversation partner } \\
\text { for someone with } \\
\text { TBI. }\end{array}$ & $\begin{array}{l}\text { Control group } \\
\text { received no skills } \\
\text { training }\end{array}$ & $\begin{array}{l}\text { Experimental group } \\
\text { more confident and } \\
\text { knowledgeable in } \\
\text { their role as } \\
\text { conversation partner } \\
\text { than control group. }\end{array}$ \\
\hline
\end{tabular}

\section{Results}

The current evidence base regarding conversation partner training in the TBI population is lacking in that only four studies met the inclusion criteria for this review. The included studies were primarily quantitative (three of the four), but were all limited by small sample sizes and recruitment difficulties. Only one study was a randomised controlled trial (Goldblum \& Alant, 2009). Three of the studies (Sim, Power \& Togher, 2013; Togher, Power, Rietdijk, McDonald, \& Tate, 2012; Togher, McDonald, Tate, Power, \& Rietdijk, 2013) were all variations of a larger study using the same participant group and the same intervention. The premise underpinning this suite of papers was that people with TBI would experience better quality of life and conversation outcomes if people with whom they interacted on a regular (i.e., daily) basis were included in communication and conversation training. 
Across all four studies, recruitment of suitable TBI participants proved difficult, as is often the case in this field. Indeed, Goldblum and Alant (2009) concluded that it was easier to enlist conversation partners than people with TBI. Engagement of TBI participants and their conversation partners was particularly problematic in the Australian studies (Sim et al., 2013; Togher et al., 2013; Togher, et al., 2012). Although RCTs were originally planned, insufficient numbers necessitated modification of the designs to non-randomised trials. Sample sizes ranged from 27 to 70 , with a total of 114 participants across the four studies. Of the 44 participants included in the suite of Australian studies, participants in the intervention group $(n=14)$ were dyads of people with TBI and a conversation partner. Given that sample sizes were small, the results should be approached with caution. With larger samples, statistically significant results are more likely to emerge. Nevertheless, it has been argued that small samples, and even case studies, can still offer information to drive future interventions (MacDonald \& Wiseman-Hakes, 2010).

In the three Australian studies, participants were allocated to one of three interventions. The interventions were either: (1) social communication training for people with TBI only and no associated communication training for conversation partners; (2) social communication training the included both people with TBI and their conversation partner; or (3) a delayed treatment control group. The duration of training was ten sessions of 3.5 hours a week. Each session comprised 2.5 hours group training and one hour individual training. Training sessions included provision of new communication information and strategies, review of home-based taperecorded samples of casual conversational interactions that occurred in the preceding week, role plays and conversational technique practice and feedback (Togher et al., 2013). The outcome was an adapted version of the Kagan scale (Kagan et al., 2004), which measured both participation in conversation and support provided during conversation (Togher et al., 2013). Adapted Kagan scales were administered pre- and post-training. Follow-up measures were also administered 6months post completion of the intervention (Togher, et al., 2013). Conversations were videotaped pre-intervention and for three weeks post-intervention. These videotapes were analysed using exchange structure analysis (Sim et al., 2013), which explored the interpersonal interactions between conversation partners in a defined context based on who held knowledge or information during a 
communicative encounter and how information was conveyed between partners in the communication exchange (Sim et al., 2013).

The non-Australian study (Goldblum \& Alant, 2009) used a number of focus groups to ascertain barriers and facilitators to effective interactions between sales staff and customers with a cognitive communication disorder associated with TBI. Once barriers and facilitators were identified, a number of training videos were developed. All participants viewed two videos with a duration of approximately 23 mins including two customer scenarios involving people with communication disorder following TBI. Confidence and knowledge about interacting with customers who have a cognitive communication disorder were measured immediately after watching the videos at these times. Participants in the intervention condition participated in a four hour training session using the video, interactive small group discussions and engagement with a research assistant who had the lived experience of TBI. They explored their beliefs about $\mathrm{TBI}$, raised their awareness about diversity, and examined barriers and facilitators to sales interactions with people with a communication disorder.

All four studies demonstrated positive results following conversation partner training, although only two were statistically significant. In the quantitative study by Togher et al. (2013), including conversation partners in training sessions improved the everyday conversational interactions of people with TBI more than including only people with TBI. The improved quality of interactions was sustained at six-month follow-up. Importantly, after six months, training people with TBI alone was no more beneficial than doing nothing. The quality of interactions between people with TBI and their conversation partners was enhanced primarily because the conversation partner was able to acknowledge and expose communication competency of the person with TBI. Although there was a general improvement in communication when conversation partners were trained, conversation partners were not necessarily able to facilitate the competence of the person with TBI in all types of conversations. Everyday conversations (i.e., casual conversations) were enhanced, but there was no improvement in purposeful conversations. This study provided evidence to support the inclusion of conversation partner training in this population, but small sample sizes mean that replication is important in future.

In an attempt to better understand the findings of the quantitative study, Togher et al. (2012) simultaneously undertook a qualitative study to explore which 
parts of the program were effective, and why. The researchers found that all conversation partners reported improved communication skills, and that they were able to better engage in deep and more interactive conversations as well as joint problem-solving interactions with the person with TBI. Most participants across both intervention groups (i.e., those with and without a conversation partner) reported increased communication confidence, which impacted positively on friendship formation, involvement in conversation and participation in social situations. Some participants reported that they had resumed pre-injury communication roles. Including conversation partners was believed to be beneficial because the partners were able to provide support and compensate for memory difficulties. However, some conversation partners initially found it confronting to have their communication styles challenged during the intervention training. Time taken to attend intervention training was an added demand for some conversation partners.

Sim, Power and Togher (2013) used exchange structure analysis to detect actual changes in discourse between people with $\mathrm{TBI}$ and their conversation partners in the way information was requested, received and given. They also examined changes in who assumed the more powerful position during sharing knowledge or ideas. They found that training for conversation partners was associated with a reduction in negative questioning behaviours, which was potentially beneficial to assist people with TBI to better organize and remember information. Additionally, providing information in a more natural conversational style had the potential to contribute to higher quality conversations. With conversation partner training, communicative burden was shared more equitably between people with TBI and their conversation partner; and people with TBI were better supported to participate in negotiation and idea clarification during conversation. Despite this positive trend, statistical significance was not demonstrated, presumably due to small sample size and heterogeneity of the TBI sample.

The study by Goldblum and Alant (2009) focused only on improving the ability of non-familiar conversation partners, namely sales assistants from a South African supermarket, to interact with customers who had sustained a TBI. Training was found to be beneficial in terms of improving the confidence and knowledge about serving someone with TBI. Statistically significant changes on both these outcomes were found for the experimental group compared to the control group. However, no 
investigation was conducted to ascertain how well the supermarket workers put this training into practice.

\section{Discussion}

The current review indicated that conversation partner training of those who interact with people who have sustained a TBI has positive outcomes. Although statistical significance was not reached in one study due to small sample sizes, all four studies showed positive outcomes. With training, the conversation partners in all studies were more confident about engaging with people with cognitive communication disorders post TBI. Although the South African study did not measure actual changes in communication encounters between conversation partners and people with TBI, the Australian study did demonstrate positive changes in content and structure that were sustained six months post interventions.

Experts in this field have recommended that conversation partner training become standard rehabilitation practice (e.g., Togher, 2014). However, there is currently a lack of statistical evidence to support this claim and further research is required. Guidance is also needed on the aspects of training that are most beneficial. With this type of information, concrete recommendations can be made about how to implement conversation partner training.

The studies included in this review all used group training, which has positive implications in terms of cost and the feasibility of delivery in clinical settings. Longterm individualised speech therapy intervention can be expensive, but if conversation partners are trained to apply useful strategies beyond the clinical context, there is potential for cost savings to health services and patients. Therapy can be continuously practiced between sessions, further improving communication skills and outcomes. As Togher et al. (2013) noted, there are also supplementary benefits to participants as group training is more enjoyable. In addition, peer support enables people with TBI and family members to congregate and learn new coping mechanisms (Grant, Elliott, Weaver, Glandon, Raper, \& Giger, 2010).

Increasing public knowledge about TBI can help to address attitudinal and environmental barriers for people with communication difficulties (McCarthy, Donofoio-Horwitz, \& Smucker, 2010). However, specific training for conversation partners of people with TBI is an interesting and valuable concept that could greatly 
reduce the stigma associated with $\mathrm{TBI}$ in the community. Choices around engaging conversation partners should be made with recognition of the naturally occurring social networks surrounding each person with TBI, and also the impact of particular services in the community. There are many challenges to face if this type of intervention is to occur, but more research is clearly required in future. Goldblum and Alant's (2009) study indicates potential benefits of training that extend beyond family and paid carers.

Muenchberger, Kendall and Collings (2011) analysed the healthcare system in Australia and its provisions for brain injury rehabilitation. They commented that much improvement was required and early intervention was not well practiced. People with communication disabilities are entitled to be involved in their treatment and clinicians need to ensure their preferences are respected through appropriate conversation. Conversation partner training could be implemented early in a patient's recovery journey to facilitate positive outcomes and prevent relationship deterioration. If neither spontaneous recovery of communication ability nor conversation partner training occurred early in the rehabilitation process, people with $\mathrm{TBI}$ risk losing essential opportunities to establish positive socially based outcomes.

There is a lack of validated instruments to assess communication outcomes for the TBI population. Frequently used tools have been developed for measurement in other clinical populations but have not yet been validated in the TBI population. Although tools have been developed to measure the interaction between conversation partners and people with aphasia (i.e., Kagan scales previously identified), Togher and her colleagues needed to adapt the scales for use in the population with TBI. Likewise, only two self-report measures currently exist to measure the social communication skills of people with TBI (Struchen, Pappadis, Mazzei, Clark, Davis, \& Sander, 2008), but these tools do not measure the impact of conversation partners on social communication skills. Thus, measurement tools require adaptation to ensure their appropriateness to this complex population. Sim et al. (2013) described exchange structure analysis as a useful method for assessing conversation, although it is challenging to adapt this in a broader context due to the need for specialist training and the time consuming nature of analysis. Thus, it may not be a suitable method for clinicians who already face multiple time and resource constraints. Only when specific tools are developed can we comprehensively and correctly assess this population and make concrete recommendations. 


\section{Limitations}

The number of papers included in this review is a clear limitation. Including additional search terms or other strategies, such as hand searching journals, may have identified additional papers. As only English papers were selected, studies may have existed in other languages. Further, the focus on the last decade may have excluded some early studies of conversation partner interventions. However, this is unlikely because the use of conversation partners to improve communication strategies for people with TBI has only recently been accepted as formal practice.

Some of the questions raised by this review need exploration to determine best clinical practice. Some recommendations for areas of future research include:

(1) Type of conversation partner - It would be useful to study the effectiveness of additional conversation partners, for example, best friends, siblings, teachers and work colleagues. Conversation occurs in a broad range of contexts yet the same conversation partner is rarely available at all times. Consequently, it would be interesting to study how efficacious training a number of partners would be in comparison to only one.

(2) Training delivery method - Both group and individual training interventions were offered in these studies. However, there has been no investigation of which method was most effective. Although group sessions have added social benefits, alternative methods may offer benefits. The more simple the method, the more likely training will be implemented in practice.

(3) Best outcome measurement - Methods of conversation analysis and outcome measurement exist but more research is needed in this area. Standardised assessments such as the LaTrobe Communication Questionnaire (Douglas, O'Flaherty \& Snow, 2000) have robust validity and reliability and may be useful for future research.

(4) Long term follow up of participants - The timeframes covered in the available studies were inadequate to offer a true account of long-term impact of conversation training. A longer period of follow-up would be helpful before conclusions can be cemented. 
(5) Larger scale studies - These small samples have indicated the efficacy of conversation partner training. However, larger samples are required for more comprehensive conclusions that can be used to support future practice.

(6) Adequate training timeframe - Due to the limited number of studies, it is difficult to determine the optimal length of training. Training duration could be a critical factor in determining the success of best practice interventions as well as the translation of this evidence into practice.

(7) Use of technology - Technology has the potential to change healthcare for the better and it is interesting to explore how it could be utilised in this arena. In Australia, leading researchers are currently exploring the role of tele-health in conversation partner training (Rietdijk, Togher \& Power, 2014). The internet has the potential to transform TBI rehabilitation and increase the accessibility of conversation partner training for a wider range of people, particularly those in remote and rural areas.

\section{Conclusion}

This is the first systematic review to our knowledge to examine the efficacy of training the conversation partners of people with TBI. Although only limited research has been conducted in this area, the few studies that have been conducted provide evidence to support the inclusion of conversation partner training in existing rehabilitation programs. At the very least, no harm will come to either partner by completing training. However, our review suggests that both individuals with TBI and their family members or carers will feel more able to communicate effectively, resulting in a higher quality of life. However, in order to design efficacious training programs, further research is necessary to inform clinicians. Qualitative research, such as that conducted by Togher et al., (2012), can be extremely useful in this regard.

The current evidence base is insufficient to make concrete recommendations at this stage. Three of the four studies (Sim et al., 2013; Togher et al., 2012; Togher et al., 2013) included in this review were conducted by the same group of expert researchers in Sydney, which may lead to potential bias in the interpretation of results, but also reflects the limited focus on TBI in this field. Importantly, Australia appears to be leading the way in conversation partner training, providing a solid 
basis for improving this aspect of life for thousands of people with TBI and their families.

\section{References}

Access Economics. (2009). The economic cost of spinal cord injury and traumatic brain injury in Australia. Melbourne: The Victorian Neurotrauma Initiative.

Armstrong, E., \& Mortensen, L. (2006). Everyday talk: Its role in assessment and treatment for individuals with aphasia. Brain Impairment, 7(3), 175-189.

Australian Intitute of Health and Welfare [AlHW]. (2007). Disability in Australia: Acquired brain injury (Bulletin 55, December 2007). Canberra: Australian Government.

Behn, N., Togher, L., Power, E., \& Heard, R. (2012). Evaluating communication training for paid carers of people with traumatic brain injury. Brain Injury, 26, 1702-1715.

Chan, J., Parmenter, T., \& Stancliffe, R. (2009). The impact of traumatic brain injury on the mental health outcomes of individuals and their family carers. Australian e-Journal for the Advancement of Mental Health, 8(2).

Cifu, D. X., Cohen, S. I., Lew, H. L., Jaffee, M., \& Sigford, B. (2010). The history and evolution of traumatic brain injury rehabilitation in military service members and veterans. American Journal of Physical Medicine \& Rehabilitation, 89(8), 688-694.

Coelho, C., Grelad, B., Corso, M., Gamble, A., \& Fenn, R. (2005). Microlinguistic deficits in the narrative discourse of adults with traumatic brain injury. Brain Injury, 19, 1139-1145.

Dahlberg, C., Cusick, C., Hawley, L., Newman, J., Morey, C., Harrison-Felix, C., \& Whiteneck, C. (2007). Treatment efficacy of social communication skills training after traumatic brain injury: A randomized treatment and deferred treatment controlled trial. Archives of Physical Medicine and Rehabilitation, 88, 1561-1573.

Douglas, J. M., O'Flaherty, C. A., \& Snow, P. (2000). Measuring perception of communicative ability: The development and evaluation of the La Trobe Communication Questionnaire. Aphasiology, 14, 251-268.

Douglas, J., Bracy, C. \& Snow, P. (2007). Exploring the factor structure of the LaTrobe Communication Questionnaire; insights into the nature of communication deficits following TBI. Aphasiology, 21, 1181-1194.

Durham, C. (2014). Unlocking my brain: through the labyrinth of ABI. Edgecliff, NSW: Jane Curry Publishing.

Goldblum, G., \& Alant, W. (2009). Sales assistants serving customers with traumatic brain injury. Aphasiology, 23(1), 87-109.

Granlund, M., Bjorck-Akesson, E., Wilder, J., \& Ylven, R. (2008). AAC interventions for children in a family environment: Implementing evidence in practice. Augmentative and Alternative Communication, 24, 207-219.

Grant, J. S., Elliott, T. R., Weaver, M., Glandon, G. L., Raper, J. L., \& Giger, J. N. (2010). Social support, social problem-solving abilities, and adjustment of family caregivers of stroke survivors. Arch Phys Med Rehabil, 87, 343-350.

Hepburn, K., Tornatore, J., Center, B., \& Ostwald, S. (2001). Dementia family caregiver training: affecting beliefs about caregiving and caregiver outcomes. Journal of American Geriatric Society, 49, 450-457. 
Hoofien, D., Gilboa, A., Vakil, E., \& Donovick, P. (2001). Traumatic brain injury (TBI) 10-20 years later: a comprehensive outcome study of psychiatric symptomatology, cognitive abilities and psychosocial functioning. Brain Injury, 15(3), 189-209.

Hyder, A. A., Wunderlich, C. A., Puvanachandra, P., Gururaj, G., \& Kobsingye, O. C. (2007). The impact of traumatic brain injuries: A global perspective. NeuroRehabilitation, 22, 341-353.

Jurado, A., Mataro, M., Verger, K., Bartumeaus, F., \& Junque, C. (2000). Phonemic and semantic fluencies in traumatic brain injury patients with focal frontal lesions. Brain Injury, 14, 789-795.

Kagan, A., Winckel, J., Black, S., Duchan, J., Simmons-Mackie, N., Square, P., \& Winckel, J. (2004). A set of observational measures for rating support and participation in conversation between adults with aphasia and their conversation partners. Topics in Stroke Rehabilitation, 11, 67-83.

Kendall, E., \& Terry, D. (2009). Predicting emotional well-being following traumatic brain injury: A test of mediated and moderated models. Social Science and Medicine, 69(6), 947-954.

Kreutzer, J., Stejskal, T. M., Ketchum, J. M., Marwitz, J. H., Taylor, L. A., \& Menzel, J. C. (2009). A preliminary investigation of the brain injury family intervention: Impact on family members. Brain Injury, 23(6), 535-547.

Leblanc, J., de Guise, E., Champoux, M., Couturier, C., Lamoureux, J., Marcoux, J., Maleki, M. M., \& Feyz, M. (2014). Early conversational discourse abilities following traumatic brain injury: An acute predictive study. Brain injury, 28(7), 951-958.

MacDonald, S., \& Wiseman-Hakes, C. (2010). Knowledge translation in ABI rehabilitation: A model for consolidating and applying the evidence for cognitive-communication intervention. Brain Injury, 24(3), 486-508.

McCarthy, J. W., Donofrio-Horwitz, L. M., \& Smucker, L. M. D. (2010). The effects of reading personal narratives written by an individual who uses $A A C$ on the attitudes of pre-professionals in business. Augmentative and Alternative Communication, 26(2), 61-74.

Moran, C., Nippold, M., \& Gillon, G. (2006). Working memory and proverb comprehension in adolescents with traumatic brain injury: A preliminary investigation. Brain Injury, 20, 417-423.

Muenchberger, H., Kendall, E., \& Collings, C. (2011). Beyond crisis care in brain injury rehabilitation in Australia. A conversation worth having. Journal of Primary Care \& Community Health, 2(1), 60-64.

Rietdijk, R., Togher, L., \& Power, E. (in press). "Supporting family members of people with traumatic brain injury using telehealth: A systematic review". Journal of Rehabilitation Medicine.

Shorland, J., \& Douglas, J. (2010). Understanding the role of communication in maintaining and forming friendships following traumatic brain injury. Brain Injury, 24(4), 569-580.

Sim, P., Power, E., \& Togher, L. (2013). Describing conversations between individuals with traumatic brain injury (TBI) and communication partners following communication partner training: Using exchange structure analysis. Brain Injury, 27(6), 717-742.

Simmons-Mackie, N., Raymer, A., Armstrong, E., Holland, A., \& Cherney, L. (2010). Communication partner training in aphasia: a systematic review. Archives of Physical Medicine and Rehabilitation, 91(12), 1814-1837. 
Struchen, M., Pappadis, M., Mazzei, D., Clark, A., Davis, L., \& Sander, A. (2008). Perceptions of communication abilities for persons with traumatic brain injury: Validity of the LaTrobe Communication Questionnaire. Brain Injury, 22(12), 940-951.

Tate, R. L., McDonald, S., \& Lulham, J. M. (1998). Incidence of hospital-treated traumatic brain injury in an Australian community. Australian and New Zealand Journal of Public Health, 22, 419-423.

Togher, L., McDonald, S., Code, C., Grant, S. (2004). Training communication partners of people with traumatic brain injury: A randomized controlled trial. Aphasiology, 18(4), 313-335.

Togher, L., Power, E., Rietdijk, R., McDonald, S., \& Tate, R. (2012). An exploration of participant experience of a communication training program for people with traumatic brain injury and their communication partners. Disability and Rehabilitation 34(18), 1562-1574.

Togher, L., McDonald, S., Tate, R., Power, E., \& Rietdijk, R. (2013). Training communication partners of people with severe traumatic brain injury improves everyday conversations: A multicenter single blind clinical trial. Journal of Rehabilitation and Medicine, 45, 637-645.

Togher, L. (2014). "An inquiry into the prevalence of different types of speech, language and communication disorders and speech pathology services in Australia". Submission to the Community Affairs References Committee of the Senate.

van Velzen, J., van Bennekom, C., Edelaar, M., Sluiter, J., \& Frings-Dresen, M. (2009). How many people return to work after acquired brain injury? A systematic review. Brain Injury, 23(6):473-88.

Vy Tu, L., Togher, L., \& Power, E. (2011). The impact of communication partner and discourse task on a person with traumatic brain injury: The use of multiple perspectives. Brain Injury, 25(6), 560-580.

Wallace, T., \& Bradshaw, A. (2011). Technologies and strategies for people with communication problems following brain injury or stroke. Neurorehabilitation, 28, 199-209.

Welch-West, P., Ferri, C., Teasell, R., Aubut, J., Villamere, J., Bayhona, N., \& Chundamala, J. (2007). Communication deficits following acquired brain injury: Intervention and treatments. Module \# 7 of the Evidence Based Review of Moderate to Severe Acquired Brain Injury. 3rd ed.

Wilkinson, R., Bryan, K., Lock, S., \& Sage, K. (2010). Implementing and evaluating aphasia therapy targeted at couples' conversations: A single case study. Aphasiology, 24(6-8), 869-886.

Yasuda, S., Wehman, P., Targett, P., Cifu, D., \& West, M. (2001). Return to work for persons with traumatic brain injury. American Journal of Physical Medicine \& Rehabilitation, 80(11), 852-864.

Ylvisaker, M. (2006). Self-coaching: A context sensitive, person centred approach to social communication after traumatic brain injury. Brain Impairment, 7, 246258.

\section{Biographical notes}

Gilly-Elle Wiltshire completed her Bachelor's degree in 2008 at the University of Manchester. This was a BSc in Speech and Language Therapy and during this 
degree she became particularly interested in the communication of those with complex needs. She has since moved to Australia and has recently graduated from a Masters degree in Human Services with a specialism in Disability Studies at Griffith University. Gilly's particular area of interest involved inclusion for people with disabilities. Her goals are to contribute to advancing research in this area which can translate into practice and improve outcomes for people with disabilities.

Dr Carolyn Ehrlich is a Senior Research Fellow at Griffith University. Her research focuses on: (1) implementation of initiatives within health systems and (2) the health of people from vulnerable populations. These areas of interest build on twenty-five years working as a registered nurse. Carolyn has developed a keen research interest in exploring the way in which people with complex health care needs access, interpret and utilize the information they receive in their ongoing health management. This work has been pivotal in expanding her research activities to include exploration and understanding of the context in which initiatives are implemented. 